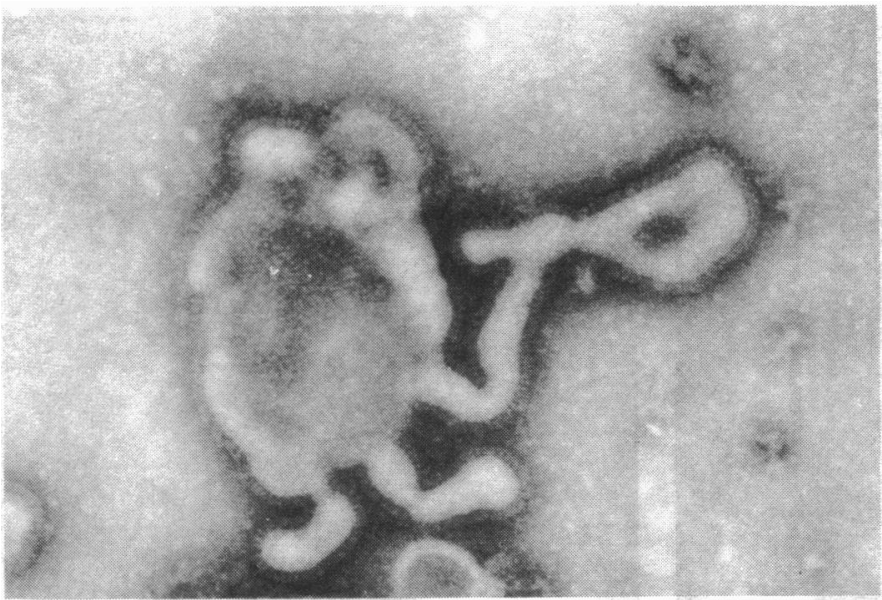

\section{Influenza virus, Santa Claus, or a mouse playing tennis?}

We have all lain on our backs, looked up at the clouds, and imagined all sorts of creatures there. Sometimes the same may happen with electron microscopy, and I recently produced this electron micrograph of an influenza virus. My colleagues and I have seen it variously as a caveman wielding a club, John McEnroe, Santa Claus, and a mouse playing tennis.-BRIAN GETTY, Department of Medical Microbiology, Royal Liverpool Hospital, Liverpool L69 3BX.

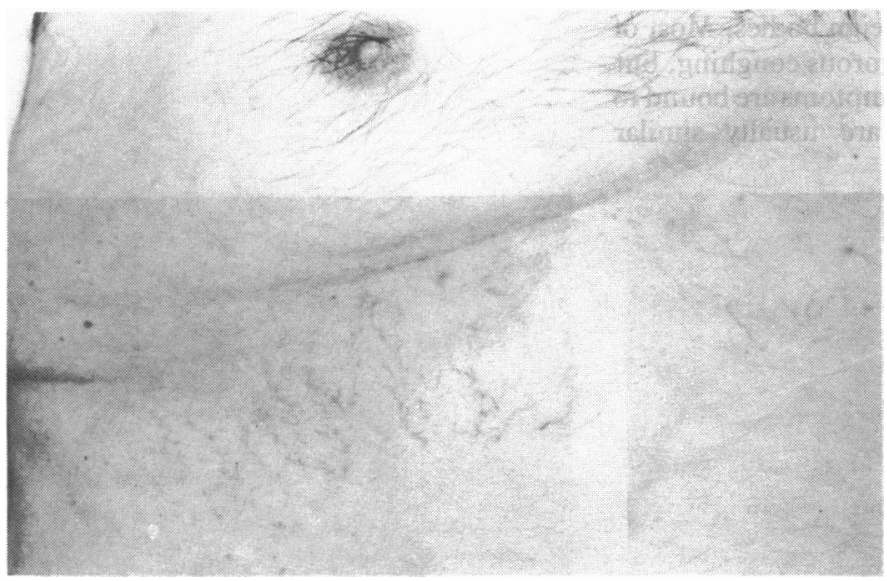

\section{Chest wall venular dilatation: a sign of chronic bronchitis?}

Venular dilatation on the lower anterior costal margin is common in men with chronic bronchitis. Using MRC criteria 87 male medical patients were identified as having chronic bronchitis or as controls. Colour transparencies of their anterior costal margins were independently examined by two consultant physicians for venular dilatation. Those graded "uncertain" or where the consultants disagreed were excluded. This left 37 bronchitic and 30 controls. Fourteen $(38 \%)$ patients with bronchitis showed venular dilatation as did $3(10 \%)$ controls-significant association between the sign and chronic bronchitis $\left(\chi^{2}=6.77, p<0.01\right)$. - I K KUNKLER, J B COOKSON, Groby Road Hospital, Leicester LE3 9QE.
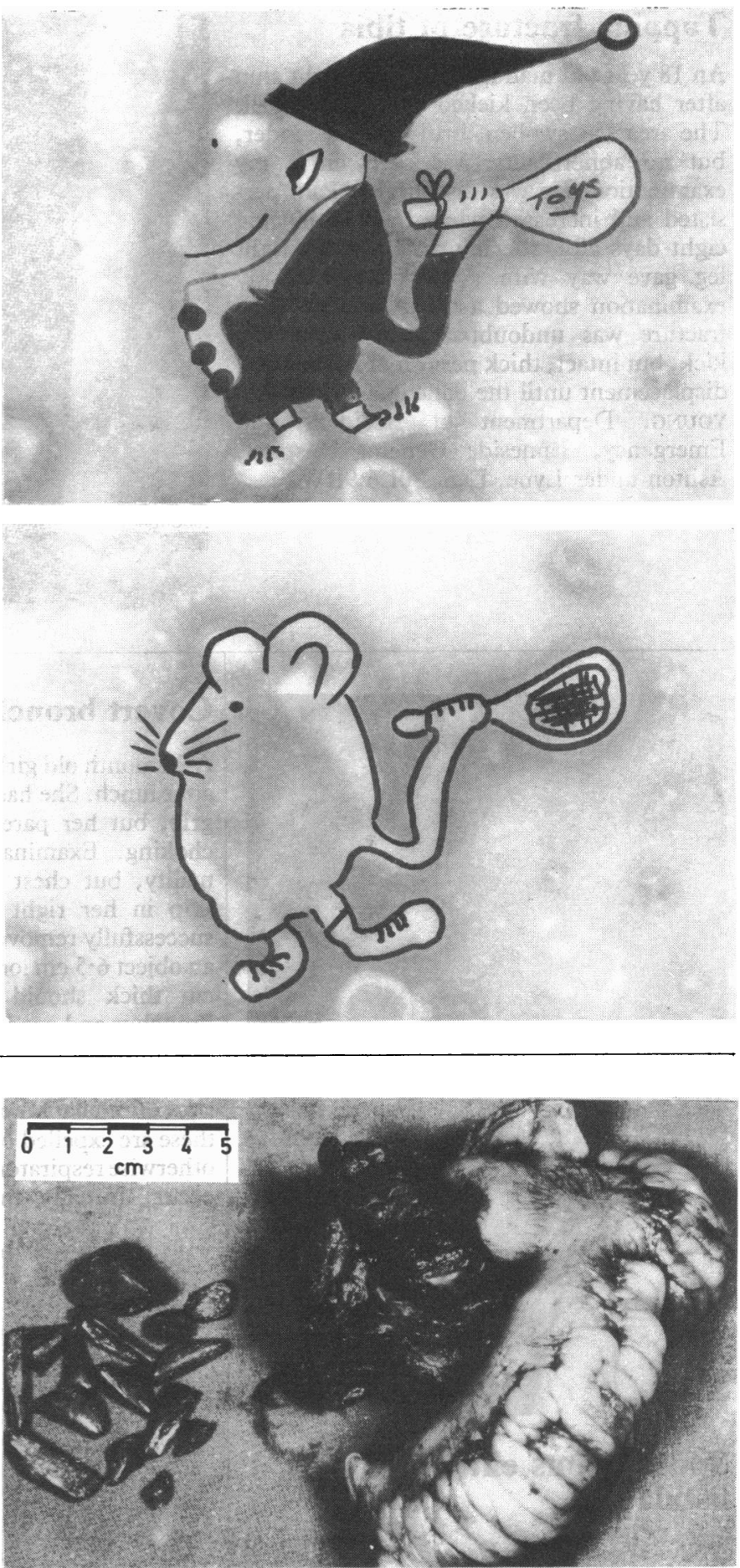

\section{Perforation of intestinal duplication by enteroliths after trauma}

A 62 year old man sustained blunt abdominal trauma in a road accident. He had generalised abdominal tenderness with guarding and absent bowel sounds. At Laparotomy there were free triangulated enteroliths within the peritoneal cavity and a $7 \mathrm{~cm}$ section of duplicated terminal ileum bearing a linear perforation and associated mesenteric tear. Further enteroliths lay within the duplication. The affected bowel was resected and continuity restored by an end to end ileoileal anastomosis. The occurrence of enteroliths in a duplicated segment of ileum and resulting in perforation is hitherto undescribed.- $P$ V MARKS, A E STUNT, Oldchurch Hospital, Romford, Essex RM7 0BE. 